\title{
Accidental Ingestion of Dapsone in Children - A Case Report Experienced in Government Tertiary Care Hospital
}

\section{Rashmi Patil*, Megha, Chikkanarasareddy PS, Panikaj AT, Vijeta V Rane and Sarala Sabapathy}

Department of Paediatrics, Bangalore Medical College and Research Institute, Bangalore, India

*Corresponding Author: Rashmi Patil, Department of Paediatrics, Bangalore Medical College and Research Institute, Bangalore, India.

DOI: 10.31080/ASPE.2020.03.0215
Received: January 21, 2020;

Published: February 06, 2020

(c) All rights are reserved by Rashmi Patil., et al.

\section{Abstract}

Dapsone, a sulfonamide derivative is being increasingly used in the treatment of a wide variety of dermatological disorders. Dapsone intoxication in children is most commonly, accidental and uncommon. The most frequent reaction that occur with higher doses of Dapsone toxicity is hemolytic anemia and methemoglobinemia. Rapid clinical assessment, measurement of methemoglobin levels and meticulous institution of treatment with Intravenous methylene blue decreases the mortality and morbidity. Here we report a 4 years old girl with methemoglobinemia secondary to severe dapsone poisoning with sinus arrhythmia and its successful management.

Keywords: Accidental; Dapsone Consumption; Children; Methemoglobinemia; Sinus Arrhythmia; Methylene Blue

\section{Introduction}

Dapsone (4, 4-diaminodiphenylsulfone), a sulfonamide derivative, was introduced in 1943 as an effective chemotherapeutic agent for leprosy [1-3]. Dapsone is increasingly used in the treatment of a wide variety of dermatological disorders in tropical world [4,5]. Because of its use in various conditions, its toxicity is commonly seen in adults [4]. However, dapsone intoxication in children is usually accidental and has been considered invariably fatal $[6,7]$. Methemoglobinemia is the major life-threatening situation associated with poisoning of DDS [8]. In initial stages of acute poisoning, there will not be any major manifestations and hence there may be delay in seeking medical attention [9]. Here we report a case of accidental severe dapsone poisoning with methemoglobinemia with sinus arrhythmia.

\section{Case Report}

A four year old girl was brought to the paediatric casualty with complaints of accidental ingestion of 20 tablets of $100 \mathrm{mg}$ each dapsone tablets. Dapsone tablets were taken by her uncle for dermatitis herpetiformis. The child presented with persistent vomiting, lethargy, drowsiness, unsteadiness and bluish discoloration of lips and oral cavity, seven hours post consumption. At admission child was drowsy with vacant stares. Patient had central and peripheral cyanosis. Euthermic with tachycardia [HR180bpm], tachypnea [RR52cpm] BP:104/68mmHg (50-90 ${ }^{\text {th }}$ centiles), oxygen saturation
(SPO2) was 65\% under room air with arterial blood gas analysis showing (pH: 7.45, $\mathrm{PCO}_{2}: 21.4 \mathrm{mmHg}, \mathrm{paO}_{2}: 102 \mathrm{mmHg}$ ) base deficit- 8.

Stomach wash was given with activated charcoal (15gm), IV ascorbic of 500mg was given and Methylene blue $2 \mathrm{mg} / \mathrm{kg}$ (15mg) was administered, slow IV and by one hour $\mathrm{SPO}_{2}$ has improved to $94 \%$. By six hours $\mathrm{SPO}_{2}$ dropped to $75 \%$ and second dose of methylene blue given, post which $\mathrm{SPO}_{2}$ has maintained at $83 \%$ with oxygen $\left(\mathrm{O}_{2}\right)$. On day three of admission, child again had desaturation $\mathrm{SPO}_{2}$ reached 75\%. Third dose of IV Methylene blue (Total of 6mg/ $\mathrm{kg}$ given). Same day child was noticed to have sinus arrhythmia, Electro cardiac monitoring was continued. Troponin-I negative, ProBNP 594pg/ml. Sinus arrhythmia settled in a day; taken as sick nodal dysfunction secondary to hypoxemia. Evidence of hemolysis characterized by drop in hemoglobin, hematocrit and increase in reticulocyte count (3.6\%) was observed on day four of admission for which PRBC transfusion was given. Next two days, we have noticed ataxia. There was no derangement of renal or liver function tests, urinalysis found to be normal. G6PD levels 111.2 units/ dL within normal limits. Hemoglobin electrophoresis was normal. Methemoglobin levels could not be assessed, not done in our setting. In the mean time, Gastric lavage, blood and urine samples sent for Forensic Lab confirmed presence of Dapsone. On day seven, child was maintaining $\mathrm{SPO}_{2} 85-89 \%$ with room air, no neurological deficits. Child was discharged at the end of two weeks. During 
follow up period, child had no cyanosis with saturation of $95-97 \%$ and neurological examination falls within the normal limits.

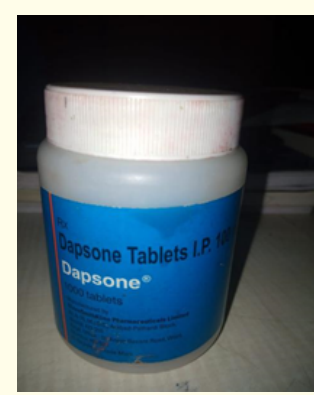

Figure 1: Dapsone tablet IP.

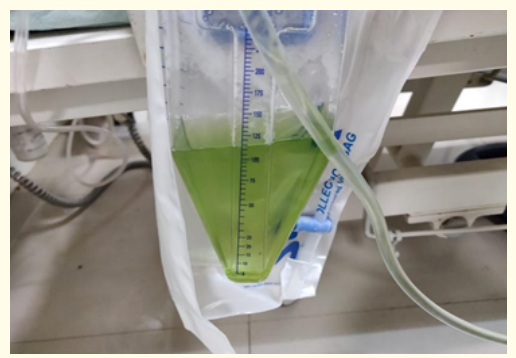

Figure 2: Urine turned green after treatment IV Methylene blue.

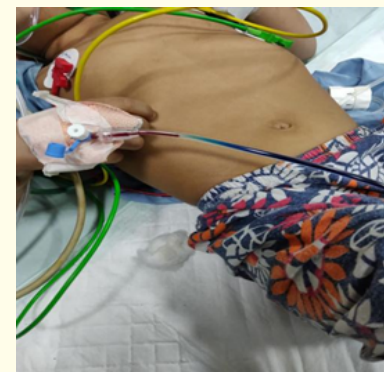

Figure 3: On flow IV methylene blue.

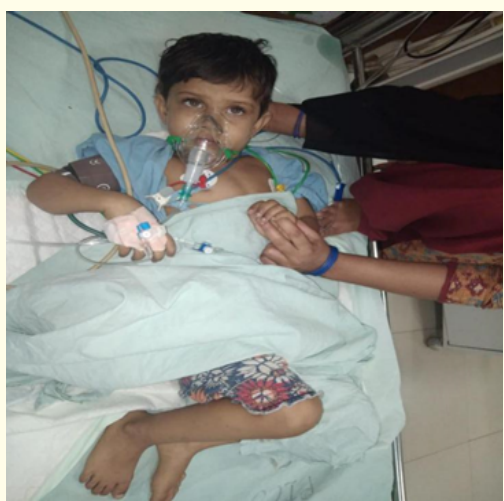

Figure 4: At the time of admission.

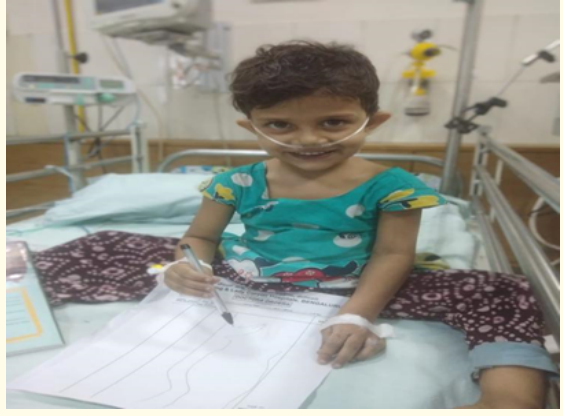

Figure 5: Final day of discharge.

\section{Discussion}

Dapsone, a sulfone is a structural analog of paraaminobenzoic acid (PABA) and a competitive inhibitor of dihydropteroate synthase in the folate pathway [7]. The indications for dapsone are varied and include the management of Pneumocystis carinii pneumonia (PCP) in immunosuppressed patients, dermatitis vulgaris, herpetiformis, psoriasis, pemphigus, acne lupus erythematosus profundus, brown recluse spider bites, pyoderma gangrenous [7] prophylaxis and treatment of falciparum malaria maduromycosis, panniculitis due to alpha- 1 antitrypsin deficiency $[1,4,9]$. Accidental dapsone poisoning in children is uncommon [8]. The poisoning may present with severe clinical symptoms like cyanosis, nausea, vomiting, headache, respiratory difficulty, drowsiness and abnormal body movements [10]. The CNS manifestations observed are irritability, hypotonia, truncal ataxia, choreiform movements and dysarthritic speech. In our case, child had cyanosis, nausea, vomiting, drowsiness, hypotonia and truncal ataxia. The plasma elimination half-life of Dapsone was found to be dose dependent which varies from 10 to $80 \mathrm{~h}$ (mean $30 \mathrm{~h}$ ), peak levels after two to six hours [11]. The drug can be detected in tissues up to three weeks after ingestion [12]. The renal excretion of unchanged Dapsone is limited to approximately $20 \%$ of the administered dose. Dapsone is metabolized in the liver for its elimination. It undergoes $\mathrm{N}$-acetylation by N-Acetyltransferase (NAT2). Dapsone hydroxylamine enters red cells leading to methemoglobin formation. The most frequent reaction that occur with higher doses of Dapsone toxicity is hemolytic anemia and methemoglobinemia [9-12]. The N-hydroxylation of dapsone to its hydroxylamine metabolite is in part responsible for methemoglobinemia in both therapeutic use and over dose. Many scientist reported that, decrease in hemoglobin (1-2 g/dL) and reticulocyte count (2\%-12\%) levels in patient with Dapsone toxicity [13]. Clinical severity depends on blood Methemoglobin levels $[13,14]$. Methemoglobin is an oxidation product of $\mathrm{Hb}$ in which there is an oxidized ferric iron in sixth co-ordination position instead of reduced ferrous iron in normal $\mathrm{Hb}$. This oxidized ferric iron containing site is then bound to a water molecule or to a hydroxyl group [14]. This complex is dark brown and unable to 
transport oxygen with a leftward shift in oxygen dissociation curve, thus leading to a decreased tissue oxygenation with subsequent hypoxic features. This also explains why the delivery of oxygen to patient does not improve the oxygen saturation level. Most of the patients are found to be asymptomatic until approximately $30 \%$ of hemoglobin is presented as Methemoglobin [15]. However, levels especially greater than $15 \%$ may be associated with cyanosis. High mortality rate is associated with levels above 70\% [16].

\begin{tabular}{|l|l|}
\hline $\begin{array}{c}\text { Methemoglobin } \\
\text { (\% in blood) }\end{array}$ & \multicolumn{1}{c|}{ Clinical features } \\
\hline 15 & Cyanosis, particularly acrocyanosis \\
\hline 20 & Cyanosis, mild fatigue \\
\hline $30-40$ & Cyanosis, weakness, tachycardia, nausea \\
\hline$>40$ & $\begin{array}{l}\text { In addition to all above, restlessness, } \\
\text { confusion, coma, death. }\end{array}$ \\
\hline
\end{tabular}

Table 1: Clinical features of dapsone poisoning is determined by methemoglobin level (\%) in blood.

This child had lethargy, tachycardia and Dizziness corresponding to Methemoglobin between 30-40\%. Level of Methemoglobin above $2 \%$ is abnormal [9]. According to a Brazilian study conducted by Maria Zilda N., et al. Dapsonemia was considered severe when 20 tablets (100 mg each) were ingested, a median of $29 \mu \mathrm{g} /$ $\mathrm{ml}$. Regarding Methemoglobinemia, intoxication was severe when 7.5 tablets were ingested, a median of $38 \%$ of the total $\mathrm{Hb}$ [10]. In our case, child had accidentally consumed 20 tablets of Dapsone $100 \mathrm{mg}$ each and hence is Severe Dapsone poisoning. In this case, excessive levels of dapsone may have led to corresponding decrease in hemoglobin levels. Acute hemolytic anemia in dapsone intoxication as observed in the present case may occur due either to the continued oxidative stress by the dapsone metabolites or bolus doses of methylene blue [12-18]. Thus, children should be observed for hemolysis by repeated hematocrit estimation and peripheral blood smear examination and need to be treated with packed cell transfusion, if needed. The standard management of orally ingested drug induced methemoglobinemia includes gastric lavage, administration of activated charcoal $(0.5-1 \mathrm{~g} / \mathrm{kg})$, methylene blue and ascorbic acid. Methylene blue is the drug of choice in the treatment of methemoglobinemia [9]. Methylene blue is a phenothiazine-related heterocyclic aromatic molecule most commonly used as a reducing agent in the treatment of methemoglobinemia and for the treatment of cyanide and carbon monoxide poisoning [19]. Methylene blue (methylthioninium chloride) when given intravenously is rapidly reduced to leuco-methylene blue by the enzyme NADPH-met-Hb reductase which reduces the met $\mathrm{Hb}$ back to $\mathrm{Hb}$ by a cyclic reaction $[4,20]$. Conventionally, methylene blue has been given intermittently every 6-8 hours as needed during prolonged dapsone intoxications. The dosing of methylene blue is not entirely clear, but $1-2 \mathrm{mg} / \mathrm{kg}$ is used for the treatment of methemoglobinemia. However, methylene blue above $7 \mathrm{mg} / \mathrm{kg}$ is associated with adverse effects such as paradoxical induction of Methemoglobinemia \{Conversely, because methylene blue is an oxidizing agent, it can itself cause methemoglobinemia by oxidizing hemoglobin at high concentrations hemolytic anemia and detrimental effects on pulmonary function [21,22]. Therefore, methylene blue should not be recommended in patients with pulmonary hypertension, underlying glucose-6-phosphate dehydrogenase deficiency and acute lung injury [22]. Concurrent use of other innocuous reducing agents with methylene blue such as ascorbic acid is known to compete directly with the chemical cause and also to provide a reducing environment in blood to allow the dye to act more efficiently [4]. In less severe cases, ascorbic acid 200-500 mg can be given intravenously as was used in our case [23]. In a case reported by Agrawal., et al, Ascorbic acid alone was used successfully to treat Methemoglobinemia due to Dapsone consumption [7]. Treatment with methylene blue can be complicated by the presence of underlying glucose-6-phosphate dehydrogenase deficiency alternative therapies like exchange transfusions and hyperbaric oxygen therapy are the remaining options in patients with glucose6-phosphate dehydrogenase deficiency or if methylene blue therapy is ineffective [24]. The exchange transfusion had been reported to be very effective in the management of methemoglobinemia [25] but was later found to be of minor benefit, probably due to large volume of distribution of dapsone [26]. Charcoal hemoperfusion has also been reported for the rapid clearing of dapsone [27]. In the presence of the increased Methemoglobin fraction, pulse oximeter values will trend toward $85 \%$ underestimating the actual oxygen saturation [9]. Routine pulse oximetry is generally inaccurate for monitoring oxygen saturation in the presence of methemoglobinemia as a saturation gap exists [28]. In our case, child had sinus arrhythmia; none of the previously reported cases had arrhythmia.

\section{Conclusion}

Any case presenting to emergency department with cyanosis and breathlessness not responding to oxygen must be suspected as a case of methaemoglobinemia. Dapsone a commonly used drug in the treatment of varied dermatological conditions; should be kept out of reach of children to prevent significant morbidity and mortality. In spite of adequate treatment, recovery can take weeks.

\section{Bibliography}

1. Malla G., et al. "Encountering dapsone poisoning in a child at the emergency department of a tertiary care hospital in eastern Nepal". Health Renaissance 12.1 (2014): 52-54

2. Gomber S., et al. "Accidental dapsone poisoning in children". Indian Pediatrics 31 (1994): 1123- 1125. 
3. Vijayakumar PG., et al. "Methaemoglobin analysis in acute dapsone poisoning". Journal of Indian Society of Toxicology (2012): 20-23.

4. Prasad R., et al. "Dapsone induced Methemoglobinemia, Sulfhemoglobinemia and Hemolytic anemia: A case report with a note on treatment strategies". Indian Journal of Pharmaceutical Sciences 34 (2002): 283-285.

5. Linakis JG., et al. "Recurrent methemoglobinemia after acute dapsone intoxication in a child". The Journal of Emergency Medicine 8 (1990): 351-352.

6. Comber S., et al. "Accidental Dapsone Poisoning in Children". Indian Pediatrics 31.9 (1994): 1123-1125.

7. Agrawal A., et al. "Ascorbic acid as an effective alternative for treatment of dapsone poisoning in a child: A case report". Indian Journal of Case Reports 3.2 (2017): 85-87.

8. Kleigman RM., et al. "Nelson Textbook of Pediatrics". $20^{\text {th }}$ ed. 2 (2016): 2348.

9. Sunilkumar MN., et al. "Acute dapsone poisoning in a 3- yearold child: case report with review of literature". World Journal of Clinical Cases 3.10 (2015): 911-914.

10. Carrazza Maria Zilda N., et al. "Clinical and laboratory parameters in dapsone acute intoxication". Rev. Saudi Publica 34.4 (2000): 396-401.

11. Barclay JA., et al. "Dapsone-induced methemoglobinemia: a primer for clinicians". Annals of Pharmacotherapy 45 (2011): 1103-1115.

12. Brunton LL., et al. “Goodman and Gilman's The Pharmacological Basis of Therapeutics".13 ${ }^{\text {th }}$ ed. (2018): 1013-1034.

13. Landers D., et al. "Dapsone induced methaemoglobinaemia". International Journal of STD \& AIDS 7 (1996): 445-447.

14. Goldfrank LR., et al. "Nitroglycerine (methemoglobinemia)". In: Toxicologic Emergencies, 4th edn. Eds Goldfrank LR, Flomenbaum NE. California, Appleton and Lange (1990): 39-396.

15. Turner MD., et al. "The recognition, physiology, and treatment of medication-induced methemoglobinemia: a case report". Anesthesia Progress 54 (2007): 115-117.

16. Curry S. "Methemoglobinemia". Annals of Emergency Medicine 11 (1982): 214-221.

17. Singh UK., et al. "Poisoning in Children". $3^{\text {rd }}$ ed., (2006): 199200.

18. Erstad BL. "Dapsone induced methemoglobinemia and hemolytic anemia". Clinical Pharmacology 11 (1992): 800-805.

19. Hanzlik PJ. "Subject of This Letter: Methylene Blue as Antidote for Cyanide Poisoning". California and Western Medicine 38 (1933): 225-226.
20. Disanto AR and Wagner JG. "Pharmacokinetics of highly ionized drugs. II: Methylene blue- absorption, metabolism and excretion in man and dog after oral absorption". Journal of Pharmaceutical Sciences 61 (1972): 1086-1090.

21. Gachot B., et al. "Short-term effects of methylene blue on hemodynamics and gas exchange in humans with septic shock". Intensive Care Medicine 21 (1995): 1027-1031.

22. Weingartner R., et al. "Blockade of the action of nitric oxide in human septic shock increases systemic vascular resistance and has detrimental effects on pulmonary function after a short infusion of methylene blue". Brazilian Journal of Medical and Biological Research 32 (1999): 1505-1513.

23. Nair PM and Philip E. "Accidental dapsone poisoning in children". Annals of Tropical Paediatrics 4 (1984): 241-242.

24. Ward KE and McCarthy MW. "Dapsone-induced methemoglobinemia”. Annals of Pharmacotherapy 32 (1998): 549-553.

25. Kumar A., et al. "Exchange transfusion of dapsone poisoning". Indian Pediatrics 25 (1998): 798-800.

26. Berlin G., et al. "Acute dapsone intoxication: A case treated with continuous infusion of methylene blue, forced diuresis and plasma exchange". Journal of Toxicology: Clinical Toxicology 22 (1984): 537-548.

27. Endre ZH., et al. "Successful treatment of acute dapsone intoxication using charcoal hemoperfusion". Australian and New Zealand Journal of Medicine 13 (1983): 509-512.

28. Singh S., et al. "Dapsoneinduced methemoglobinemia: "Saturation gap" - The key to diagnosis". Journal of Anaesthesiology Clinical Pharmacology 30.1 (2014): 86-88.

\section{Assets from publication with us}

- Prompt Acknowledgement after receiving the article

- Thorough Double blinded peer review

- Rapid Publication

- Issue of Publication Certificate

- High visibility of your Published work

Website: www.actascientific.com/

Submit Article: www.actascientific.com/submission.php Email us: editor@actascientific.com Contact us: +919182824667 